\title{
Evaluation and Preventing Measures of Technological Risks of Food Production
}

\author{
Igor Vladimirovich Surkov ${ }^{1}$, Alexander Yurievich Prosekov ${ }^{1}$, Evgeniya Olegovna Ermolaeva ${ }^{1}$, Galina \\ Anatol'evna Gorelikova ${ }^{1} \&$ Valery Mikhailovich Poznyakovskiy ${ }^{1}$ \\ ${ }^{1}$ Federal State-owned Budgetary Educational Institution of Higher, Vocational Education "Kemerovo Institute of \\ Food Science and Technology", Kemerovo, Russia \\ Correspondence: Igor Vladimirovich Surkov, Federal State-owned Budgetary Educational Institution of Higher, \\ Vocational Education "Kemerovo Institute of Food Science and Technology", Kemerovo, 650056, Russia. \\ E-mail: osmk@rambler.ru
}

Received: November 13, 2014

Accepted: November 16, 2014

Online Published: December 10, 2014

doi:10.5539/mas.v9n4p45

URL: http://dx.doi.org/10.5539/mas.v9n4p45

\begin{abstract}
The goal of the present research is to comprehensively evaluate technological risks of food production through the example of enriched probiotic-containing confectionary.

In order to achieve the goal, the following tasks were set:

to concretize the "risk" notion related to production,

to systemize reasons of technological risks that have negative impact on the quality,

to investigate reasons of defects, define their ponderability coefficient using the expert evaluation (through the example of enriched probiotic-containing confectionary),

to develop a matrix model of technological risks of defects occurrence while producing food,

to determine coefficients of the relevance of reasons that cause defects of enriched probiotic-containing confectionary,

to propose a system of measures for decreasing the level of technological risks and preventing defects.
\end{abstract}

Keywords: risks, matrix model, food, defects

\section{Introduction}

International and native practice pays more and more attention to risks management in the system of food safety. A new approach while analyzing risks in the chain of producing food aims at discovering potential risks and evaluating them. The International Standardization Organization (ISO) issued ISO 31000:2009 "Risk management. Principles and guiding instructions" standard applied to a number of production areas including food production where risk management is defined as a culture of organization (persuasion and value), processes and structure aiming to realize potential possibilities while managing unfavorable effects.

The whole operation of a food management is connected with risks, and the basic goal of the enterprise management is to achieve the organization manageability and take efficient preventive solutions by analyzing indefiniteness and probability of future events or circumstances that can lead to a risk event or non admittance of negative phenomena and subsequences on this basis.

Such scientists as V.M. Kantere, V.M. Matison, N.I. Dudchenko, D.A. Edelev, Akao Yoji, F.L. Bryan, S. Mizuno, P. Sullivan Larry and others made a great contribution to issues of risk management in food production.

A lot of authors single out microbial contamination, remnants of pesticides in food products among risks of food production $(11,17)$.According to $\mathrm{Cucu}$ et al. (2013), food allergy is an important problem of food safety due to possible lethal outcome. The only efficient preventive method is complete removal of allergens involved from the dose (2).The work of Mensah et al. (2011) presents factors that influenced the current state of food safety in food production in Great Britain. In order to actively work with risks related to food safety, integrated systems of food safety management are implemented at enterprises. However, enterprises state that regulatory acts predominantly target at customers, being without an adequate evaluation of the influence on all interested parties 
within the chain. Consequently, areas have significant expenses that could be avoided in the contrary case. Although it is burdensome to continue regulating food safety, the discrepancies cost will be considerable for enterprises. The implementation of the system managing food safety will allow to successfully manage risks at food enterprises (15).

The implementation of risks, safety, etc. risks management at food enterprises are reliable factors for mitigating the level of risks related to production, provision of quality and safety of the produced products $(2,10,11,15,17$, 18 ) including biologically active additives and specialized food products. Herewith, issues related to managing key processes become important (19).

\section{Methods}

We used general, standard and special methods of research including organoleptical, physical, chemical, microbiological, analytical, statistical, sociological, and expert evaluation method. The researches were conducted three-five times. The results were processed by methods of calculating statistical veracity of measurements using such software as Microsoft Excel and Statsoft Statistica.

In the work we used the author methodology - for evaluating the importance of defects importance and their probability while producing probiotic confectionary - offering a matrix model of defects processes received on the basis of the calculations with the use of the expert evaluation.

\section{Results}

Food quality and safety are the most important conditions for preventing food poisoning and food infections. Flavor, nose and body defects make any product unattractive for the customer that leads to the decrease in the product competitiveness and production inefficiency. Technological risks evaluation, risks management and their prevention are important and urgent problems of today's production.

As a rule, the "risk" term is used when there is at least probability of negative consequences of the event. In accordance with P 51901.1-2002 "Risk Management. Analysis of Technological Systems Risk" GOST, the "risk" is understood as a combination of the event probability and its consequences.

Herewith, there is a necessity to define the "technological risk" term that the authors expect to use while evaluating production risks.

Based on this, the authors have concretized the following definitions:

Production technological risk is a combination of any dangerous event and its consequences that take place during the production. As a rule, this risk occurs as defects of the manufactured products that causes losses and damages.

Food safety technological risk is a risk related to the food production technology, it can lead to the customer's health danger. This term is more essential for food industry.

Technological risk of specialized food defect occurrence is a technological risk of specialized food production that has fluctuations of the product quality indicators from the standard that can cause a decrease in the customer's satisfaction level.

The performed analysis of literature data and results of our own experiments allowed to determine the role and impact of the following factors in the product quality and safety: acceptance and storage, technological parameters of the primary processing of raw materials, type of adding aromatizants/natural colors, viscolization, dozing, storage terms and conditions, packaging, and transportation of the ready products.

The next important factor of forming food quality and safety indicators is technological equipment. Efficiency, construction and its peculiarity, technical specifications of operative parts and mechanisms, type of operation, system of automated technological processes management, hygienic state of the equipment surface, technical condition, etc. are determinative in the process of forming quality and safety indicators.

The analysis of the customers' claims, database of violations and non-compliance with terms and conditions, regimes, requirements, substances dozing and other aspects allow to classify technological risks during food production in accordance with their causes into 2 groups:

1) technological risks of harming the customer's health (safety risks),

2) technological risks of food products defects occurrence.

All reasons of risks occurrence can be grouped into 4 groups:

- $\quad$ raw materials quality (quality indicators), 
- type and condition of the equipment,

- controlled technological regimes and parameters while producing,

- $\quad$ products storage regimes.

The best results while creating and producing competitive products are achieved by the enterprises that have comprehensive information about potential and the most dangerous risks during the operation, and timely develop managing influence related to their elimination.

Risk management process means researching characteristics and parameters of the risk object and subject, internal and external factors that greatly influence the object and the risk subject's behavior, its planning, optimization, accounting and control, regulating and motivation, performance of works on risk management.

We evaluated technological risks through the example of enriched probiotic-containing confectionary because they are referred to specialized food being full according to their composition and consumer attributes that can be treated as one of the most efficient way of food optimization and improving today's person health.

Special requirements are placed to them as they have functional characteristics. Due to this, they get additional controlled indicators (for example, Lactobacterium and bifidus bacteria for probiotic-containing confectionary).

In order to evaluate the importance of causes and probability of defects while producing enriched probiotic-containing confectionary, we offered a matrix model of defects occurrence processes. The expert evaluation method that helps to characterize the impact of factors on defects occurrence with the help of weight coefficients was chosen as a method of evaluating the importance of defects occurrence reasons.

We received data from customers and the enterprise specialists as a questionnaire table containing the list of confectionary defects in columns (filled out by customers), and the list of possible reasons of defects occurrence (filled out by the enterprises specialists). Experts were offered to fill out the questionnaire data and intermediate coefficients used for describing the power of interrelation of the factors influence on the defects occurring enriched probiotic-containing confectionary. As a result of the mathematical processing of the data received from the experts, a matrix model of technological risks of defects occurring in enriched probiotic-containing confectionary was made.

The D sequence of numbers being an adjustable comprehensive indicator of the danger of causes of defects occurring in enriched probiotic-containing confectionary was received by summing up indicators in the matrix model columns. Each element of this sequence can be expressed as the following formula:

$$
D_{i}=\sum_{i=1}^{N} c_{i j} ; i=1, P ; j=1, N
$$

where $\mathrm{D}_{\mathrm{i}}$ is a coefficient of importance of the i defect occurrence reason (element of $\mathrm{D}$ sequence of numbers),

$\mathrm{c}_{\mathrm{ij}}$ is a coefficient of importance of the $\mathrm{i}$ reason influencing the occurrence of the $\mathrm{j}$ defect (matrix model element), $\mathrm{N}$ is a number of the matrix model lines,

$\mathrm{P}$ is a number of the matrix model columns (number of elements of $\mathrm{D}$ sequence).

The received $\mathrm{D}$ indicator is presented in the matrix model.

Technological risks of defects occurring in enriched probiotic-containing confectionary were evaluated on the basis of the matrix model. The ratio of the received $\left(D_{i}\right)$ importance coefficients to the sum of all elements of the matrix model $(\mathrm{S})$ is a percentage indicator of the contribution made by each cause related to defects occurrence i.e. the numeric evaluation of the danger of $i$ cause of defects occurring in enriched probiotic-containing confectionary.

Ranging according to the decrease in the $\mathrm{S}$ indicators received in the matrix model allows to make a conclusion that the following causes have the greatest influence on defects occurring in enriched probiotic-containing confectionary: type and condition of the equipment for preparing syrup, temperature of the ready products storage, storage humidity, type and condition of the equipment for mixing compositions, mixing time, type and terms and conditions of transportation, package material. It is necessary to pay more attention to these causes while producing enriched probiotic-containing confectionary.

Results of evaluating defects causes importance is presented as a diagram on Figure 1. 
Figure 1 shows that the most important causes of defects in enriched probiotic-containing confectionary include type and condition of the equipment for mixing compositions and syrup production as well as transportation type and terms and conditions.

In order to timely eliminate the risk of defects occurrence, it is important for producers to be aware about its probability.
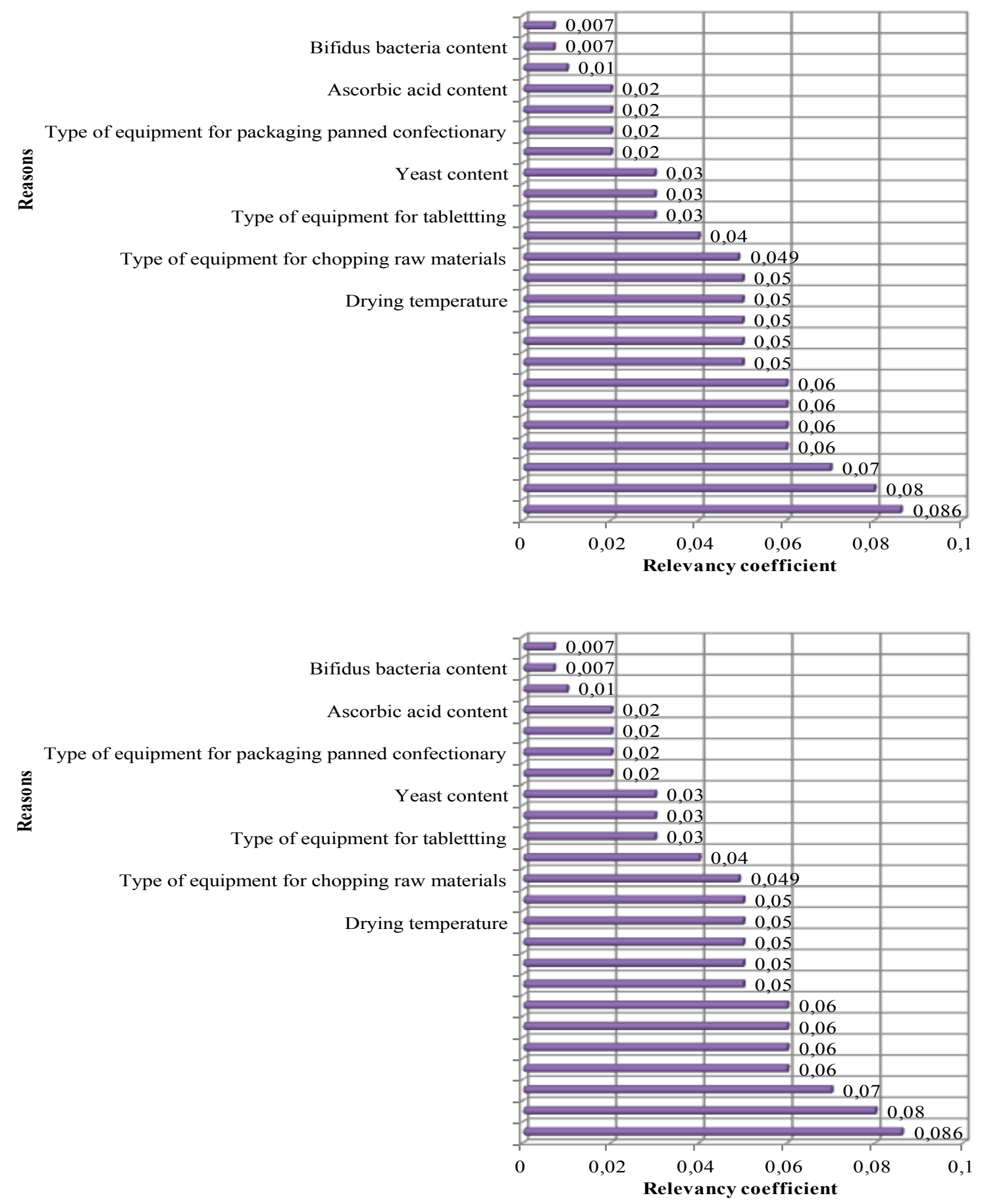

Figure 1. Coefficients of relevancy of enriched probiotic-containing confectionary defects

Note: "type of equipment" means "type and state of equipment".

Summing up the indicators of defects causes importance in lines of the matrix model defines the sequence of 
numbers of defects probability parameters being an adjustable comprehensive evaluation of probable defects of enriched probiotic-containing confectionary, each element of which $\left(\mathrm{G}_{\mathrm{i}}\right)$ is a parameter of the relevant defect probability and can be expressed as the following formula:

$$
\begin{aligned}
& \mathrm{N} \\
& \mathrm{G}_{\mathrm{i}}=\sum \mathrm{c}_{\mathrm{ij}} \quad ; \mathrm{i}=1, \mathrm{P} ; \mathrm{j}=1, \mathrm{~N} \\
& \mathrm{i}=1
\end{aligned}
$$

where $\mathrm{G}_{\mathrm{i}}$ is a coefficient of the $1^{\text {st }}$ defect importance,

$c_{i j}$ is a coefficient of the $i$ reason importance that influences the $j$ defect (matrix model element),

$\mathrm{N}$ is a number of the matrix model lines (the number of elements of defects probability parameters),

$\mathrm{P}$ is a number of columns of the matrix model (number of $\mathrm{D}$ column elements).

Ranging in accordance with the indicators decrease in the matrix model of the whole line of defects probability parameters allows to make the conclusion that the most probable defects include appearance defects $(79,77,72$, $53,46,41)$, flavor taste $(64,50,24)$ and nose defects $(73,56,38)$ of enriched probiotic-containing confectionary. The indicators we received are presented in the matrix model (Table 1).

The matrix model of defects occurrence processes shows that the greatest probability of defects in enriched probiotic-contaning confecitonary occurs under the influence of the following causes: type and condition of the equipment for syrop production, type and condition of the equipment for ixing compositions ( 0.08 each), type and terms and conditions of transporting (0.07), time of mixing, package material, temperature of the ready product storage, storage humidity ( 0.06 each).

On the basis of the matrix model analysis and evaluation of the technological risks of defects occurring in enriched probiotic-containing confectionary, we offered measures of preventing the most important defects. As a result of generalizing the defined measures we offered the following scheme of defects prevention measures while producing enriched probiotic-containing confectionary:

- raw materials control (evaluating organoleptic, physical and chemical and microbiological indicators),

- optimization of the system controlling temperature and humidity while storing raw materials,

- control and optimization of the press intensity at the tabletting stage,

- control over compositions viscolization,

- control over confectionary production and terms of its further storage, and

- control over the transportation process.

The implementation of the offered correcting and preventive measures demonstrated a decrease in the level of the manufactured products defects that practically proves the experts' conclusions and the author's methodology of evaluating technological risks and their causes.

\section{Discussion}

One of the first researches on developing the technological risks evaluation methodology through the example of producing yoghurt products was made by Kushchev (2009) (12). This work shows a comprehensive evaluation of technological risks during the production; we studied and systemized risks that are characteristic of food production, we discovered unallowable risks and defined the processes that influence the products quality and safety that is systemizing material of foreign and native companies' experience. According to the results of our researches, we singled out 4 groups of determining factors while evaluating risks at food enterprises when controlled parameters of each process stage is controlled for providing the quality stability and the final product safety. This material is demonstrated in more details in the following sources $(6,9)$.

The work of Van Kleef et al. (2007) demonstrates the development and realization of the food strategy of risk management, it offers the model of foundational psychological factors that influence the customers' evaluation of food risks of the quality management using methods of structural equation modeling (SEM) (20).

Afterwards this theme was developed through the example of various enterprises of food and processing industry $(3,4,7,13)$.

The existing works (Kantere and others, 2008; Edelev and others, 2011, 2012; Gurianov and Pozniakovskiy, 2013) related to the evaluation of technological risks while producing food do not fully reflect approaches on 
achieving the final product safety including the implementation and monitoring of the controlled parameters $(5$, $8,9,10,14)$. These approaches make up a subject of the further research.

The proposed model was approbated through the example of enriched probiotic confectionary; it was implemented and is currently used at "YUG" NPO LLC research and manufacturing association (Biysk) that produces biologically active additives and other specialized food products.

Table 1. Matrix model of technological risks of defects appearing in probiotic-containing confectionary

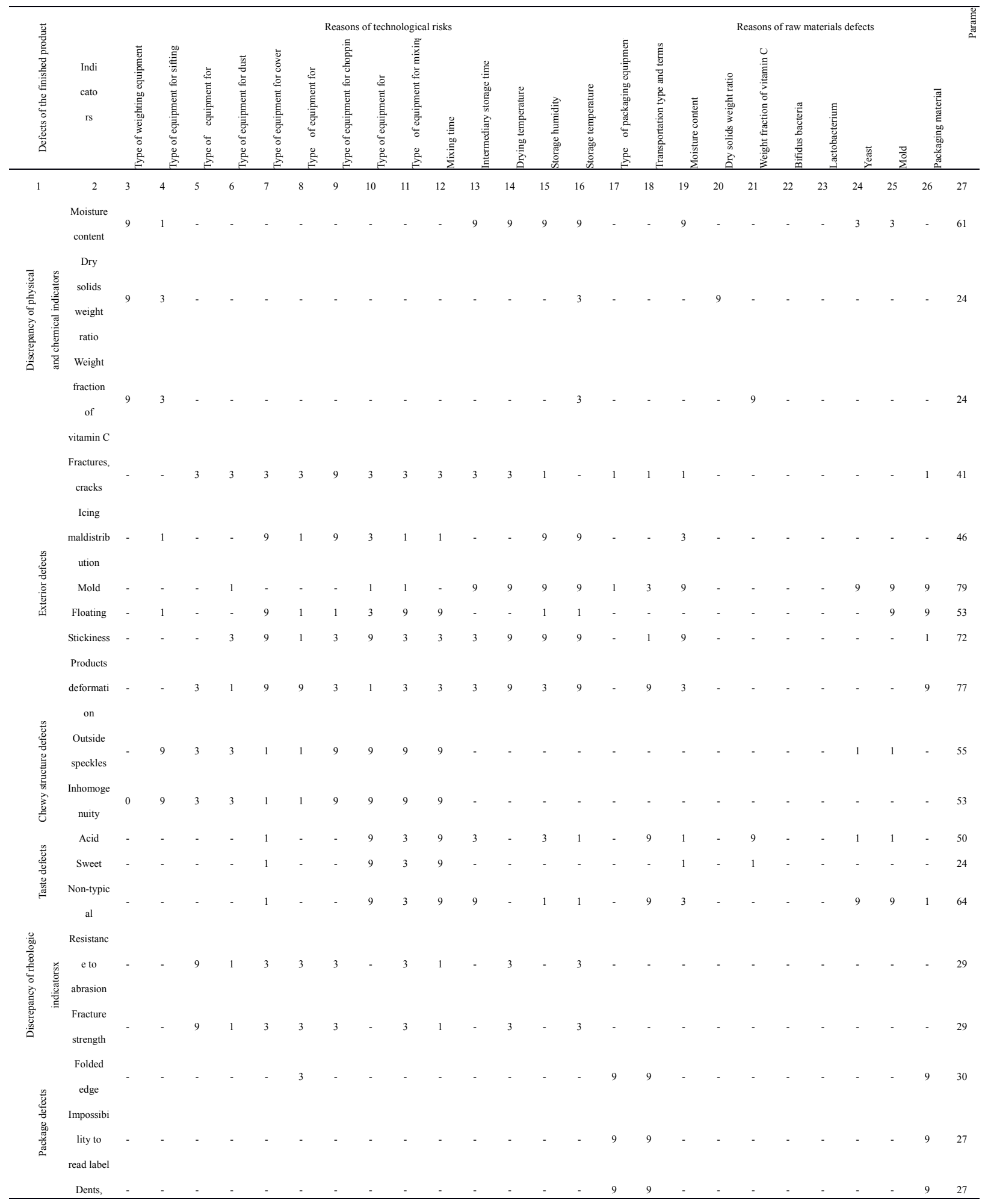




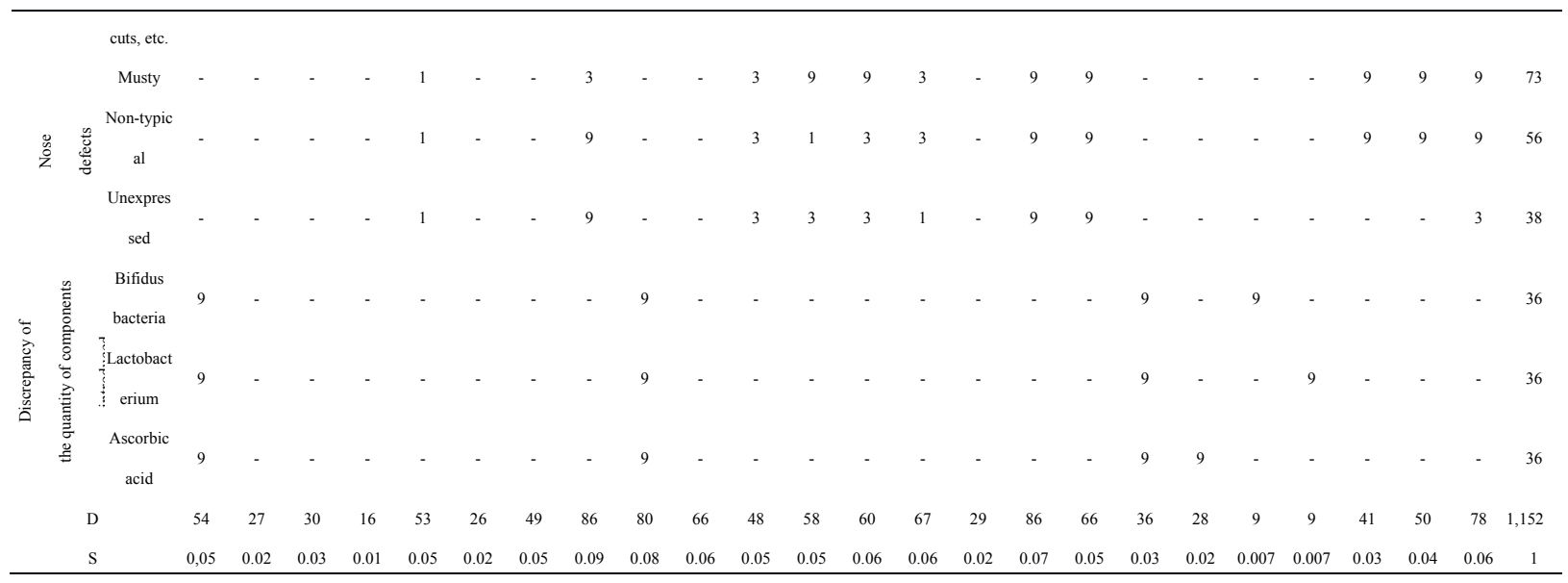

\section{Conclusion}

Materials of the researches we made are related to managing technological risks that are basic reasons of products defects.

We defined production technological risks that affect the quality of confectionary, and as a consequence, the level of customers' satisfaction. We displayed that effective prevention of technological risks while producing can be subject to the implementation of the safety management system. We developed a matrix model of technological risks of defects in specialized confectionary; we determined coefficients of the importance of reasons, and ranged them. We defined the system of defects prevention measures.

The data we received can be used at any food enterprise subject to evaluating technological risks of producing various products with the aim to improve their quality.

Particularly, the methodology to evaluation risks and their probability we offered can be used as a basic model for developing quality management systems.

The perspectives of further work are related to the approbation and implementation of the proposed methodology at food enterprises of various specificities.

\section{Acknowledgement}

The authors render thanks and deep express profound gratitude to Professors Kantera V.M., Matison V.A. and director of YUG NPO LLC for providing information and consulting on practical issues of risk management.

All comments and wishes shall be taken with appreciation and will be taken into account in the next work.

\section{References}

Akao, Y. (Ed.) (1990). Quality Function Deployment (QFD). Integrating Customer Requirements into Product Design (pp. 369). Portland, OR: Productivity Press.

Cucu, T., Jacxsens, L., \& De Meulenaer, B. (2013). Analysis To Support Allergen Risk Management: Which Way To Go? Journal of Agricultural and Food Chemistry, 61(24), 5624-5633. http://dx.doi.org/10.1021/jf303337z

Edelev, D. A., et al (2012). Identification, Evaluation and Analysis of Risks of Quality Parameters and Safety Discrepancies through the Example of Producing Sweet Cognac-Based Liqueurs. Food production, 3, $46-50$.

Edelev, D. A., Kantere, V. M., \& Matison, V. A. (2011). Eliminating Risks during the Food Life. Food Production, 10, 42-44.

Edelev, D. A., Kantere, V. M., \& Matison, V. A. (2011). Evaluation of Risks is the Most Important Element of Food Management Risk. Food Production, 9, 14-16.

Edelev, D. A., Kantere, V. M., \& Matison, V. A. (2011). Risk Management in Food Production. Food Production, 6, 46-48.

Edelev, D. A., Kantere, V. M., \& Matison, V. A. (2011). Risks Management in the Process of Risk Management of Food Enterprises. Food production, 11, 54-57.

Edelev, D. A., Kantere, V. M., \& Matison, V. A. (2012). Risks Management in School Catering System. Food 
production, 11, 36-38.

Ermolaeva, E. O., \& Pozniakovskiy, V. M. (2014). System of Managing Safety of Products of Functional Purpose: monograph (pp. 341). Saarbruken, Deutschland: LAP LAMBERT Academic Publishing.

Gurianov, Y. G., \& Pozniakovskiy, V. M. (2013). Innovational Healthy Products on the Basis of Local Raw Materials: monograph (pp. 191). Kemerovo: Kuzbassvuzizdat.

Kantere, V. M. (1990). Theoretical Basics of Microbiologic Production Technology (pp. 271). Moscow: Agropromizdat.

Kantere, V. M., Matison, V. A., \& Sazonov, Y. S. (2006). System of Food Safety Management on the basis of ISO 22000 International Standard: monograph (pp. 454). Moscow: Food Enterprises Management, Quality, Safety and Ecology Institute; Moscow State University of Food Productions.

Kantere, V. M., Matison, V. A., \& Sazonov, Y. S. (2008). Integrated Management Systems in Food Production: monograph. Food Enterprises Management, Quality, Safety and Ecology Institute (pp. 522). Moscow: Moscow State University of Food Productions.

Kushchev, S. N. (2009). Development of Methodology to Estimate Technological Risks while Producing Yoghurt Products (pp. 206). Thesis of Candidate of Technical Sciences, Moscow State University of Applied Biotechnology, Moscow.

Mensah, L. D., \& Julien, D. (2011). Implementation of food safety management systems in the UK. Food Control, 22(8), 1216-1225.

Mizuno, Sh., \& Akao, Y. (ed.) (1994). QFD. The Customer-Driven Approach to Quality Planning and Deployment (pp. 365). Tokyo, Japan: Asian Productivity Organization.

Pozniakovskiy, V. M., Gurianov, Y. G., \& Bebenin, V. V. (2011). Nutritional Supplements and Biologically Active Additives: Characteristics, Use, Control (for students of higher educational establishments, edition 3, corrected and supplemented) (pp. 275). Kemerovo: Kuzbassvuzizdat.

Sawe, C. T., Onyango, C. M., \& Njage, P. M. K. (2013). Current food safety management systems in fresh produce exporting industry are associated with lower performance due to context riskiness: Case study. Food Control, 40(6), 335-343. http://dx.doi.org/10.1016/j.foodcont.2013.12.019

Surkov, I. V., Ermolaeva, E. O., Prosekov, A. Y., Gorelikova, G. A., \& Poznyakovskiy, V. M. (2014). Key processes management in development and implementation of management systems at food enterprises. Life Sci J, 11(12), 300-304.

Van Kleef, E., Houghton, J. R., \& Krystallis, A., et al. (2007). Consumer evaluations of food risk management quality in Europe. Risk analysis: An official publication of the Society for Risk Analysis, 27(6), 1565-80.

\section{Copyrights}

Copyright for this article is retained by the author(s), with first publication rights granted to the journal.

This is an open-access article distributed under the terms and conditions of the Creative Commons Attribution license (http://creativecommons.org/licenses/by/3.0/). 